\title{
SOLID STATE TRANSDUCERS
}

The Solid State Transducers symposium exceeded our expectations. The presentations provided an excellent mix of high quality technical papers and review papers dealing with the fundamental physics and chemistry of sensors. Some of the interesting topics included the magnetic sensor, the dielectric measurement technique, gas sensors, MIS gas diode detector, special diaphragm pressure transducer and sodium potassium micro ISFET's.

Attendance was 40 to 50 percent higher than expected. Although the room seated 120 people, ten were standing during the first day. Attendance continued throughout the symposium at about 70-100, indicating a strong interest in the program. The evening panel discussion was attended by about 70 people and although it was formally ended at 10 p.m., many participants held informal discussions until a later hour.

The half-hour time allotment per speaker worked out well and most speakers limited their talks to 20-25 minutes, leaving time for discussion which increased audience participation.

During the evening meeting, it was suggested that there should be a fixed schedule for similar future solid state transducer symposia. An ad hoc committee was formed to consider this and to discuss ways to implement the idea. Several industrial companies indicated their willingness to provide additional funds beyond existing government support to make such meetings possible.

Wen H. Ko

Case Western University

S. C. Chang

GM Research Laboratories

Chairmen

\section{SCIENTIFIC BASIS FOR NUCLEAR WASTE MANAGEMENT}

The 4th International Symposium on the Scientific Basis for Nuclear Waste Management was highlighted by a maturing of the process of characterizing alternative forms for immobilization of the waste. It was generally shown that when a total waste disposal system is taken into account, several waste forms are more than adequate. The decision regarding which waste form will be used, particularly for the low heat generating defense wastes, therefore seem to revolve most around cost and ease and safety of processing.

It is anticipated that future symposia will reflect a growing interest in the science underlying low level waste disposal and in analyses of total system performance, including geologic phenomena.

Another highlight of this Chairman symposium was the enthusiastic response to the poster sessions. Since these sessions offer so much potential for one-to-one information exchange and discussion, there will probably be a higher proportion of poster session papers in future years.

\section{Steven V. Topp}

DuPont Savannah River Laboratory

\section{NOMINATIONS} FOR THE

VON HIPPEL

AWARD
The membership is invited to nominate distinguished materials scientists for the Society's most prestigious honor, the Von Hippel Award. Nominations must be received by May 15 , so do not delay.

The Award recognizes scientists of the first order, whose research has contributed significantly to a greater understanding of materials from the atomic to the microstructural level. The Award recognizes a body of work rather than an isolated achievement.
Even more importantly, the Award recognizes the interdisciplinary nature of materials science, the cooperative spirit in which various disciplines work in concert to solve problems common to the several fields.

Nominations should include a description of the career achievements of the nominee, and should be sent to K.N.Tu, Awards Committee Chairman, Thomas J. Watson Research Center, International Business Machines Corp., Yorktown Heights, New York 10598, (914) 945-1602. 